\title{
INTEGRATION AND OPTIMIZATION OF VARIOUS CONDITIONS MONITORING METHOD
}

\author{
Mohammed Fazal Ur Rahman, Prof. Syed Nawazish Mehdi and Fatima Firdous Nikhat \\ Department of Mechanical Engineering, Singhania University, Pacheri Bari, Rajasthan, India \\ Department of Mechanical Engineering, K.B.N. Collage of Engineering, Kalaburagi, \\ Karnataka, India
}

\begin{abstract}
Condition Monitoring technique acts as revolutionary mechanism because of effective, quick, reliable and cost effective application to uphold, maximize, optimize uninterrupted operation of high end equipment's, in particular and all operating equipment's, in general specially in power plant. Various methods are been adopted in this technique in which vibration analysis, wear debris analysis, thermography etc., are most common, widely recognized and in practice for carrying out condition monitoring program. These methods acts as preventive and proactive approach in identifying wear in machines and diagnose fault occurred in the machinery.

Generally these condition monitoring techniques are isolated, carried out independently by respective departments, analyzed separately without establishing correlation between these techniques, leading to generation of separate reports for each technique. This leads to only a part of turbine faults typically get diagnosed. Therefore integration of these techniques can provide greater, deeper, and more reliable quick information leading to effective diagnosis of turbine in more accurate way. This paper deals with integrations and optimization of all various condition monitoring techniques that can be carried out simultaneously on turbine leading to early detection of problem and proper diagnosis to be carried out resulting in minimizing operating cost, avoid unplanned breakdown, and to maintain uninterrupted operation of turbine.
\end{abstract}

Keywords: Condition Monitoring, Integration, Optimization, Vibration Analysis, Wear Debris Analysis, Thermography, Steam turbine, optimization, Maintenance.

Cite this Article: Mohammed Fazal Ur Rahman, Syed Nawazish Mehdi and Fatima Firdous Nikhat, Integration and Optimization of Various Conditions Monitoring Method, International Journal of Advanced Research in Engineering and Technology, 10 (6), 2019, pp 30-40.

http://iaeme.com/Home/issue/IJARET?Volume $=10 \&$ Issue $=6$ 


\section{INTRODUCTION}

In a power plant condition based maintenance has been widely accepted as most reliable, cost effective technique for upholding, boosting the life of machinery's in power plant. There are various machinery's in a power plant which are been classified in classes based on their criticalness. The machines are divided into four classes, and the vibration velocity is spread over four ranges.

Class-I: Individual parts of machines, engines integrally connected to the complete machine in its normal operation. (Production electrical motors of up to $15 \mathrm{KW}$ are typical examples of machines in its category)

Class-II: Medium size machines (typically electrical motors with 15 to $75 \mathrm{~kW}$ output) without special foundations, rigidly mounted machines, engines (up to $300 \mathrm{kw}$ ) on special foundations.

Class-III: Large prime - movers and other large machines consisting of rotating masses mounted on heavy and rigid foundations, relatively stiff in the direction of vibration measurements.

Class-IV: Large prime - movers and other large machines consisting of rotating masses mounted on Foundation, relatively soft in the direction of vibration measurements (for example turbo generator sets and gas turbines with outputs greater than $10 \mathrm{MW}$ ). There are various methods that are in practice for condition monitoring of equipment's and each of these method have its own significance. Among all these methods, vibration analysis is more popular and widely used for critical machines running with high speeds such as turbine, where vibrations produce acts as parameter for diagnosing the operating condition of the machine under study. Vibrations are measured and analyzed by which nature and severity of the fault in the machine can be determined.

Another method by name wear debris analysis is also very well-known and effective condition monitoring technique. In this method wear particles are carried by the lubricating oil used to lubricate the relative surface motion between the parts of machine. By analyzing the wear particle, direct information on deteriorating failure modes of the machine can be detected at very early stage. This method is more effective for machineries with low speed (< $5 \mathrm{rpm}$ ) where vibration analysis cannot be applicable. Oil analysis deals with changes in physical properties of circulating lubricating oil within the equipment resulting in determine the working condition of lubricating oil of equipment. Infrared Thermography analysis deals with thermal abnormalities leading to failure of equipment.

\section{TECHNIQUES}

There are various techniques used to monitor the operational condition of equipment's in a power plant without disturbing the working state of equipment's. These techniques include:

(I) Vibration monitoring

(II) Thermography

(III) Tribology

(IV) Process parameters

(V) Visual inspection

(VI) Ultrasonic Monitoring

(VII) Operating Dynamics Analysis and

(VIII) Other non-destructive testing techniques. 


\subsection{Vibration Monitoring}

Vibration analysis is the dominant technique used for predictive maintenance management. Since most of equipment's in typical power plants are mechanical, this technique has vast application and benefits condition monitoring program of almost total plant [1]. In this technique, vibrations produced by mechanical equipment are monitored, analyzed to decide their real condition. Using vibration analysis to detect machine problems is always very effective. By the early 1980s, the instrumentation and analytical skills required for vibrationbased predictive maintenance were almost developed. These techniques and instrumentation had proved to be extremely reliable and accurate in detecting abnormal machine behavior. However, the cost of instrument and the expertise demanded to acquire and analyze vibration data, makes extensive application of predictive maintenance of this type impossible. Therefore, only the equipment's which are most critical in industries could justify the expense required to implement a vibration based predictive maintenance program.

\subsection{Thermography}

Thermography is also a condition monitoring technique that is been adopted to monitor the condition of power plant equipment's, structures, and systems. In this technique, instrumentation designed to monitor the emission of infrared energy is used, i.e., temperature, to determine their working condition [2]. Thermal anomalies i.e., areas that are hotter or colder than acceptable range, are detected helping to locate and define incipient problems within the machinery under study.

\subsection{Tribology}

Tribology deals with design and operating dynamics of the bearing-lubrication rotor support structure of machinery. Various tribology techniques can be adopted for predictive maintenance such as: lubricating oil analysis, ferrography, and wear particle analysis.

Lubricating oil analysis is a technique that determines the condition of oils used to lubricate mechanical equipment's. An accurate quantitative breakdown of individual chemical elements, both oil additive and contaminates, accommodated in the oil is provided by profiles obtained by this type of analysis. Comparison of the volume of metals trace in consecutive oil samples indicates wear patterns of oil-wetted parts in machinery and will provide indication of looming failure in the machine.

Previously, tribology analysis was been a relatively slow and expensive operation. Analyses were conducted using traditional laboratory techniques and required extensive, qualified professionals. But now microprocessor-based systems are available that can automate most of the spectrographic and lubricating oil analysis, resulting in minimizing the human effort and cost of analysis.

The main applications for lubricating oil are quality control, reduction of lubricating oil archives, and calculation of the most worthwhile interval for oil replacement. To evaluate the condition of oils used in lubricating hydraulic and dielectric can be frequently analyzed, using these techniques. The results derived by this analysis helps to determine if the oil meets the lubricating requirements of the machine Helps to suggests lubricants can be changed or upgraded to meet the specific operating requirements [3]. In addition detailed analysis of the chemical and physical properties of different oils used in the plant can, in some cases, allow consolidation or reduction of the number and types of lubricants required to maintain plant equipment. Elimination of unnecessary duplication can reduce required inventory levels and therefore maintenance costs. 


\subsection{Process Parameters}

Mostly machine or systems efficiency is not consider being part of the maintenance responsibility by plants. Although, machines that are not functioning within allowable efficiency parameters, severely effects the productivity of plants. Therefore, routine monitoring of process parameters should be included in a comprehensive predictive maintenance program. In order to understand the importance of process parameters monitoring, let us consider a process pump that is critical to plant operation. Predictive maintenance based on vibration analysis will provide the mechanical operating condition of the pump and infrared thermography analysis will provide the temperature condition of the motor and bearings. Neither of these two methods provides any indication related to operating efficiency of the pump. Accordingly, the pump could be functioning at less than 50 percent efficiency and the predictive maintenance program would not detect the problem [4].

This type of process inefficiencies are considered to be the most serious limiting factor in a power plant. Their negative impact on plant productivity and profitability is often greater than the total cost of the maintenance operation. However, many plants do not recognize this unfortunate fact without regular monitoring of process parameters.

\subsection{Visual Inspection}

Systematic visual inspection of the machines and systems in a plant is an integral and important part of any predictive maintenance program. In most of the cases, visual inspection helps to recognize potential failures that can be missed, unnoticed by using the other predictive maintenance techniques discussed. Regular visual inspection of all critical machines will supplement the other techniques and ensure that potential defects are determined before serious failure occurs. The capability of recording visual observations as part of the routine data-acquisition process is mostly included in the vibration-based predictive maintenance systems.

\subsection{Ultrasonic Monitoring}

This predictive maintenance technique is based on principles similar to vibration analysis. Both techniques observe the noise generated by plant machinery or systems to determine their actual operating condition. Ultrasonic process monitors the higher frequencies, i.e., ultrasound, produced by unique dynamics in process machineries, unlike vibration monitoring. The usual monitoring range for vibration analysis is from less than 1 to 20,000 Hz. whereas ultrasonic techniques monitor the frequency range between $20,000 \mathrm{~Hz}$ and 100 $\mathrm{kHz}$. The principal application for ultrasonic monitoring is in leak detection. The turbulent flow of liquids and gases through a restricted orifice, i.e., leak, will produce a high-frequency signature that can easily be identified using ultrasonic techniques. Therefore, this technique is ideal for detecting leaks in valves, steam traps, steam turbines, piping, and other process systems.

\subsection{Operating Dynamics Analysis}

This analysis method is driven by machine or system design and is not limited to traditional analysis techniques. The diagnostic logic is derived from the specific design and operating characteristics of the machine-train or production system. Based on the unique dynamics of each machine train or system, all parameters that define optimum operating condition are routinely measured and evaluated. Using the logic of normal operating condition, operating dynamics can detect, isolate, and provide cost-effective corrective action for any deviation from optimum. 
Operating dynamics analysis combines traditional predictive maintenance techniques into a holistic evaluation technique that will isolate any deviation from optimum condition of critical plant systems. This concept uses raw data derived from vibration, infrared, ultrasonic, process parameters, and visual inspection but applies a unique diagnostic logic to evaluate plant systems.

\subsection{Other Techniques}

Numerous other non-destructive techniques can be used to identify incipient problems in plant equipment or systems. However, these techniques either do not provide a broad enough application or are too expensive to support a predictive maintenance program. Therefore, these techniques are used as the means of confirming failure modes identified by the predictive maintenance techniques. Other techniques that can support predictive maintenance include acoustic emissions, eddy-current, magnetic particle, residual stress, and most of the traditional non-destructive method.

\section{DESCRIPTION OF EQUIPMENT FOR EXPERIMENTAL EXERCISE}

\subsection{Turbine}

Specification of main turbine:

Make: KRAFTWERK UNION, WEST GERMANY

Type: Three Cylinder, reheat, Condensing turbine

No of stages: HP 18 Nos. IP 14x2 Nos. LP 6x2 Nos.

Nominal rating: $500 \mathrm{MW}$

Peak Loading: 536.7 MW

Rated Speed: $3000 \mathrm{rpm}$

Max/Min Speed: 3090/2850 rpm

Speed exclusion range: 400 to $2850 \mathrm{rpm}$.

\section{PRINCIPLE}

\subsection{Condition monitoring of 500MW Steam Turbine using Vibration Analysis}

There have been lots of advancements in microprocessor technology coupled with the expertise of companies that specialize in machinery diagnostics and analysis technology in recent years, leading to evolution of means to provide vibration-based predictive maintenance that can be cost-effectively used in thermal power plants. These microprocessor-based systems have simplified the data acquisition, automated data management, and minimized the need for vibration experts to interpret data.

Systems available commercially are capable of routine monitoring, trending, and evaluation of the working condition of all mechanical equipment specially turbine in a power plant [5]. This type of program can be adopted to schedule maintenance on all mechanical equipment's. Monitoring the vibrations produced from plant machinery, helps to determine direct relation between the working condition and vibration data recorded of each machine in the power plant. Any deterioration in working condition of plant equipment's can be detected by this condition monitoring techniques. Vibration analysis can effectively identify specific degradation of machine components or the failure mode of plant machinery before serious break down of turbine. 


\subsection{Vibration Limits as per Standards VDI 2056/59. BS 4675, ISO 2372 for Assessing Turbine Machinery Vibration}

Table 1. Vibration acceptable limits

\begin{tabular}{|c|c|c|c|c|c|c|}
\hline \multirow[t]{2}{*}{$\begin{array}{l}\text { Turbine } \\
\text { Generators }\end{array}$} & \multicolumn{6}{|c|}{$\begin{array}{l}\text { Absolute Bearing Housing Vibration measured by portable equipment's } \\
\text { in Horizontal ' } H \text { ' and ' } V \text { ' directions } \\
\text { Vibration units - Displacement in Pk-Pk } \mu \mathrm{m} \& \text { Velocity in } \mathrm{Pk} \mathrm{mm} / \mathrm{sec}\end{array}$} \\
\hline & $\begin{array}{l}\text { Very } \\
\text { good }\end{array}$ & Good & Fair & Useable & $\begin{array}{c}\text { Still } \\
\text { acceptable }\end{array}$ & $\begin{array}{c}\text { Not } \\
\text { Permissible } \\
\end{array}$ \\
\hline $\begin{array}{l}\text { Stage-II } \\
(3 \mathrm{X} 500 \\
\mathrm{MW})\end{array}$ & $\begin{array}{c}\text { Up to } \\
18 \mu \mathrm{m} \\
\& \\
2.5 \\
\mathrm{~mm} / \mathrm{sec}\end{array}$ & $\begin{array}{c}18 \mu \mathrm{m} \& \\
2.5 \\
\mathrm{~mm} / \mathrm{sec} \\
\text { to } \\
25 \mu \mathrm{m} \& \\
4 \mathrm{~mm} / \mathrm{sec}\end{array}$ & $\begin{array}{c}25 \mu \mathrm{m} \& \\
4 \mathrm{~mm} / \mathrm{sec} \\
\text { to } \\
40 \mu \mathrm{m} \& \\
6.3 \\
\mathrm{~mm} / \mathrm{sec}\end{array}$ & $\begin{array}{c}40 \mu \mathrm{m} \& \\
6.3 \\
\mathrm{~mm} / \mathrm{sec} \\
\text { to } \\
65 \mu \mathrm{m} \& \\
10 \\
\mathrm{~mm} / \mathrm{sec}\end{array}$ & $\begin{array}{c}65 \mu \mathrm{m} \mathrm{\&} \\
10 \mathrm{~mm} / \mathrm{sec} \\
\text { to } \\
100 \mu \mathrm{m} \& \\
15 \mathrm{~mm} / \mathrm{sec}\end{array}$ & $\begin{array}{c}\text { Above } \\
100 \mu \mathrm{m} \& \\
15 \mathrm{~mm} / \mathrm{sec}\end{array}$ \\
\hline
\end{tabular}

\subsection{Condition Monitoring of 500MW Steam Turbine using Lubricating Oil}

\section{Analysis}

Oil analysis one of the most important and effective condition monitoring technique in preventive maintenance. The samples of machine lubricant are taken at planned intervals to evaluate the condition of the lubricating film that is critical to turbine-train operation. Typically almost 10 tests are conducted on collected lubricating oil samples from the turbine:

Viscosity: This is one of the most critical characteristic of lubricating oil. To determine the thinning or thickening of the sample during use, the actual viscosity of oil samples is compared with an unused sample. Oils with excessively low viscosity will reduce the oil film strength, weakening its potential to prevent metal-to-metal contact. Similarly oils with excessively high viscosity may prevent the free flow of oil to crucial locations in the bearing support turbine, decreasing its ability to lubricate.

Contamination: Oil when get contaminated by water or coolant creates major problems in a lubricating system. Many of the additives which are now used in formulating lubricants contain the same elements that are used in coolant additives. Therefore, for comparison the laboratory must have an accurate analysis of new oil.

Fuel Dilution: Dilution of oil in an engine weakens the oil film strength, sealing ability, and detergency. It may be caused by improper operation, fuel system leaks, ignition problems, improper timing, or other deficiencies. Fuel dilution is considered serious when it reaches a level of 2.5 to 5 percent.

Solids Content: This is a general test. All solid materials present in the oil are measured as a percentage of the sample volume or weight. The presence of solids in a lubricating system will significantly increase the wear on lubricated parts. Any unexpected rise in reported solids is cause for concern.

Fuel Soot: An important indicator for lubricating oil used in turbine, fuel soot is always present to some extent. A test to measure fuel soot in turbine is important, since it indicates the fuel-burning efficiency of the oil used. Most tests for fuel soot are conducted by infrared analysis.

Oxidation: Lubricating oil oxidation can result in lacquer deposits, metal corrosion, or thickening of the oil. Most lubricants contain oxidation inhibitors. However, when additives 
are used up, oxidation of the oil itself begins. The quantity of oxidation in an oil sample is measured by differential infrared analysis.

Nitration: Fuel combustion in engines results from nitration. The products formed are highly acidic and may leave deposits in combustion areas. Nitration will accelerate oil oxidation. Infrared analysis is used to detect and measure nitration products.

Total Acid Number (TAN): This is a measure of the amount of acid or acid like material in the oil sample. Because new oils contain additives that affect the TAN number, it is important to compare used oil samples with new, unused, oil of the same type. Regular analysis at specific intervals is important to this evaluation.

Total Base Number (TBN): This number indicates the ability of oil to neutralize acidity. The higher the TBN the greater its ability to neutralize acidity. Typical causes of low TBN include using the improper oil for an application, waiting too long between oil changes, overheating, and using high sulphur fuel.

Particle Count: Particle count tests are important to predict possible machine problems, especially hydraulic systems. In this test, counts of high particles indicate that machinery may be wearing abnormally or that failures may occur because of temporarily or permanently blocked orifices. No attempt is made to determine the wear patterns, size, and other factors that would identify the failure mode within the machine.

\subsection{Condition Monitoring of 500MW Steam Turbine Using Wear Particle Analysis}

Wear particle analysis is related to oil analysis in which the particles to be analyzed are accumulated through drawing a sample of lubricating oil from turbine. Wear particle analysis provides direct information about the wearing condition of the turbine bearings. Particles in the lubricant of a turbine can provide significant information about the condition of the turbine. This information is derived from the study of particle shape, composition, size, and quantity [3]. Wear particle analysis is normally conducted in two stages. The first method used for wear particle analysis is routine monitoring and trending of the solid particles of turbine lubricant. In simple terms the quantity, composition, and size of particulate matter in the lubricating oil are indicative of the mechanical condition of the turbine. A normal turbine will contain low levels of solids with a size less than 10 micrometers. As the turbine's condition degrades, the number and size of particulate matter will increase.

The second wear particle method involves analysis of the particulate matter in each lubricating oil sample. Five basic types of wear can be identified according to the classification of particles: rubbing wear, cutting wear, rolling fatigue wear, combined rolling and sliding wear, and severe sliding wear (shown in Table-2). Only rubbing wear and early rolling fatigue mechanisms generate particles predominantly less than 15 micrometers in size.

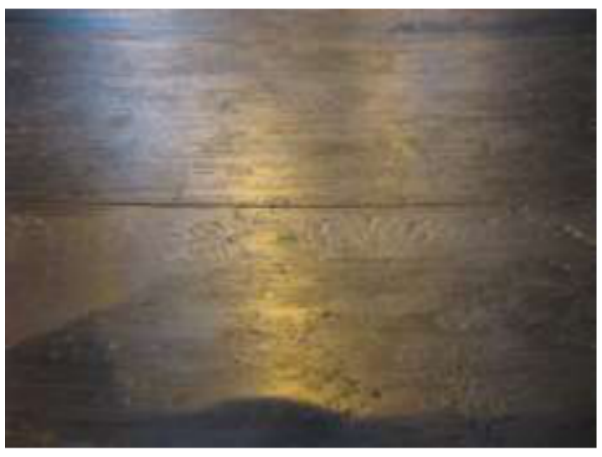

Figure-1. Wear off surface of Bearing

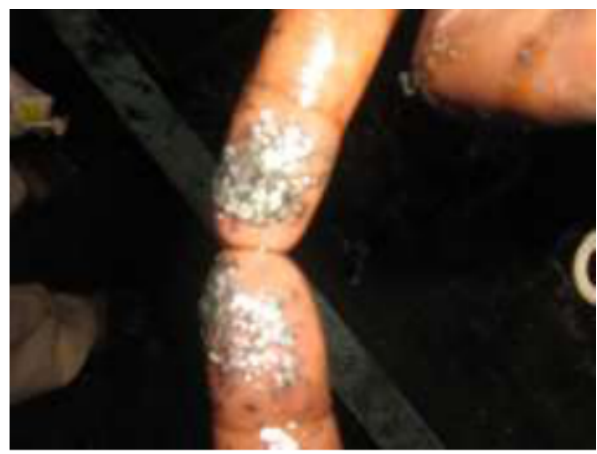

Figure-2. Wear Debris of Bearing 
Integration and Optimization of Various Conditions Monitoring Method

Table-2. Five types of wear

\begin{tabular}{|c|c|}
\hline Type & Description \\
\hline Rubbing wear & Result of normal wear in machine. \\
\hline Cutting wear & $\begin{array}{c}\text { Caused by one surface penetrating another } \\
\text { machine surface. }\end{array}$ \\
\hline Rolling fatigue & Primary result of rolling contact within bearings. \\
\hline $\begin{array}{c}\text { Combined rolling and } \\
\text { sliding wear }\end{array}$ & $\begin{array}{c}\text { Results from moving of contact surface within a } \\
\text { gear system. }\end{array}$ \\
\hline Severe sliding wear & Caused by excessive loads or heat in a gear system. \\
\hline
\end{tabular}

\subsection{Condition Monitoring of 500MW Steam Turbine Using Ferrography}

Firstly, ferrography separates particulate contamination by using a magnetic field. A magnetic field is used to separate contaminants; this technique is primarily limited to ferrous or magnetic particles. Secondly, particulate contamination larger than 10 micrometers can be separated and analyzed. Normal ferrographic analysis will capture particles up to 100 micrometers and provides a better representation of the total oil contamination than spectrographic techniques.

There are three major limitations with using tribology analysis in a predictive maintenance program: equipment costs, acquiring accurate oil samples, and interpretation of data.

\subsection{Condition Monitoring of 500MW Steam Turbine Using Thermography}

Infrared thermography technology is forecast on the fact that any object possesses a temperature higher than absolute zero, emit energy or radiation. One form of this emitted energy is Infrared radiation. Infrared emissions, or below red, are the shortest wavelengths of all radiated energy and are invisible without special instrumentation. The intensity of infrared radiation from an object is directly proportional to its surface temperature [2]. However, it is complicated to measure temperature using infrared methods because thermal energy that can be detected from any object is of three sources: energy emitted from the object itself, energy reflected from the object, and energy transmitted by the object. In predictive maintenance program, only the emitted energy is important. And the remaining transmitted and reflected energies will distort raw infrared data. Therefore, acquired data must be filtered out of the transmitted and reflected energies, before making a realistic analysis.

The surface of an object influences the amount of emitted or reflected energy. A perfect emitting surface is called a blackbody and has an emissivity equal to 1.0. These surfaces do not reflect. Instead, they absorb all external energy and reemit as infrared energy. Surfaces that reflect infrared energy are called grey bodies and have an emissivity less than 1.0. Most plant equipment including turbine falls into this classification. Careful consideration of the actual emissivity of an object improves the accuracy of temperature measurements used for predictive maintenance.

Diversification in surface condition, paint, or other protective coatings and many other parameters affect the real emissivity factor of turbine. Thermography techniques user must also consider the atmospheric condition between the turbine and the instrument used for measurement, in addition to transmitted and reflected energy. Infrared radiations are absorbed by water vapor and other gases. Since the atmospheric environment is constantly changing, using thermo graphic techniques requires extreme care each time infrared data are acquired. 
Infrared monitoring systems or instruments furnish special filters to be used to circumvent the cynical effects of atmospheric attenuation of infrared data. However, the specific factors affecting the accuracy of the infrared data and other signal conditioning filters required to nullify that specific attenuating factors must be recognize by the plant user.

Collecting optics, radiation detectors, and some form of indicator comprise the basic elements of an industrial infrared instrument. The radiant energy is collected by optical system is focused upon a detector, that converts it into an electrical signal. The output signal will be amplified and processes it into a form which can be displayed by instrument's electronics.

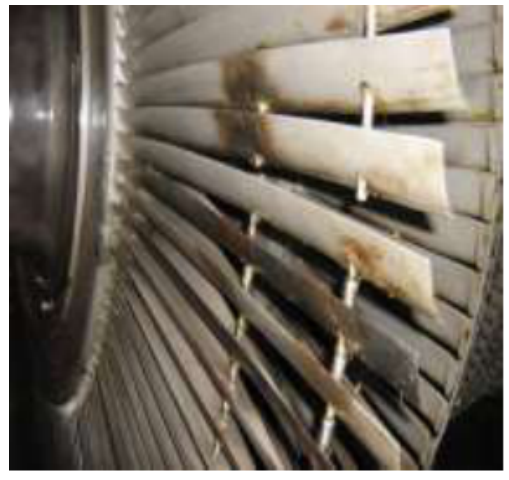

Figure-3. Cracks developed in the blades

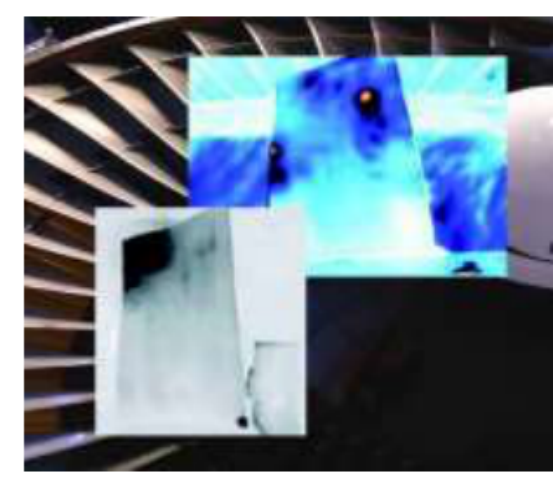

Figure-4. Thermography image of Blades

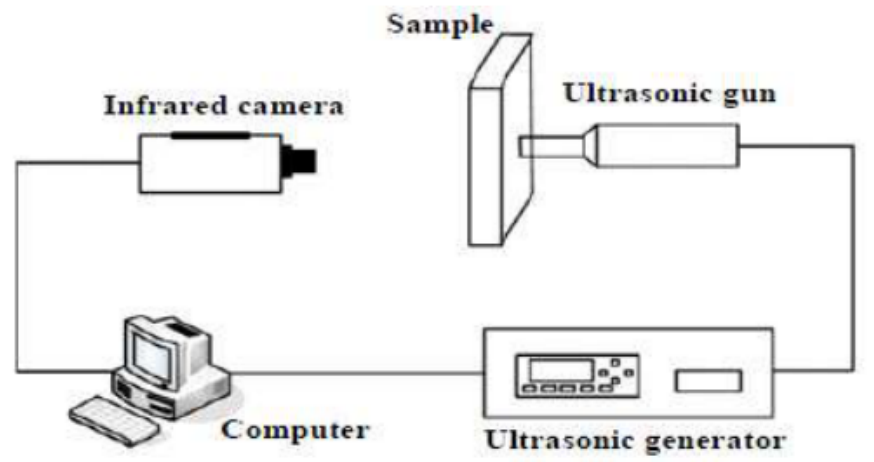

Figure-5. Infrared Thermography Detection Setup

\subsection{Integration of Vibration Analysis, Wear debris, Infrared Thermography and Process parameter Analysis}

Whenever there is increase in vibrations during operation of turbine, these vibrations signals are contributed by many structures and components to which this turbine is coupled. Depending upon there displacement, velocity, frequency, amplitude, the phase change observed during vibration analysis, the type of problem developed can be analyzed. If the frequencies are 1XRPM, amplitudes larger in radial direction, possible cause is considered to be Unbalance. For frequencies 1XRPM 2RPM and 3XRPM with amplitude larger in axial direction, possible cause for this condition is considered to be Misalignment. Similarly Mechanical looseness leads to high amplitudes at frequencies odd multiple of RPM.

Wear off in industrial rotating equipment's are common because of rolling and sliding motion between them. Generally this type of damages cannot be detected by vibration analysis specially rotating equipment's with low speed. These wear particles acts as leading indicator in providing information directly on wear modes with in turbine. These wear particle contaminate the circulating lubricating oil. Samples of contaminated lubricating oil consisting 
of wear debris are collected. Concentration of particles, size distribution, particle detail morphology, rate of wear, wear mechanism and wear source of wear debris are analyzed in detail with help of particle analyzer. This helps in understanding the wear cause and source.

All equipment's including turbine, have their own operating thermal signature when operating under normal conditions. Infrared thermography considers this regular signature as baseline to detect any thermal abnormalities which cannot be detected by any other condition monitoring method. These localized thermal abnormalities are due to two reasons, either due to overheat or under heated conditions. Thermal variations of bearings, gearbox, blades of turbine leading to development of concentric hot spots at overheated locations of the turbine. And these hot spots act as weak point from where equipment breakage can take place leading to failure of equipment. There will be no abrupt increase in vibrations because of development of these concentric hot spots and no sign of deterioration is visible, therefore cannot be detected by the vibration analysis. And there is no chamfering of material on regular bases; this irregular development of hot spots with in the turbine equipment cannot be detected by vibration analysis or by wear debris analysis. Therefore Infrared thermography covers these types of weak points within the turbine during operation under extreme high temperatures and high pressures. During this process heat emitted by the turbine is scanned in order to detect the increase in temperature throughout the assembly of turbine as explained above and shown in Figure- 3 and 4.

Even when the turbine do not show any deteriorating effects and running in ideal condition, there may drop in working efficiency of turbine which directly effects the production. This type of problem goes uncheck until one special condition monitoring technique is applied, since this type of problem cannot be identified neither by vibration analysis nor by wear debris analysis nor by infrared thermography. This type of drop in working efficiency of turbine can only be identified by process parameter analysis

Almost all condition monitoring techniques are now in practice for various machines particularly in power plant because of their respective significance. But all these techniques are isolated, carried out separately without any interrelation or correlation between them. All readings are taken by expertise using sophisticated instruments for respective techniques. Reading obtain are analyzed separately and the corrective diagnosis measures are derived separately by respective department. There is no procedure for correlating, integrating all these techniques so that integrated analysis can be carried out which can result in much better understanding the working condition, health of turbine on wider range. This can help is deriving integrated diagnosis measure in all possible failure angles to insure smooth operation of equipment.

\section{CONCLUSIONS}

In past and presently many efforts are been carried out in this regard specially to integrate and optimize major condition monitoring techniques, such as vibration analysis and wear debris analysis but only on experimental or trail level, by subjecting the turbine under various working condition in addition to normal operating conditions. Such as under lack of proper lubrication, lubricating oil with added contamination particles etc., since proper practical implementation still remain big challenge. Experimental results found by integrating techniques were very accurate, reliable and very complementary.

But, still there are lots of more condition monitoring techniques as discussed in this paper, which requires practical online integrating setup, platform that can complement with each other in order to monitor all the possible failures of high end equipment's such as turbine working under extreme conditions in $360^{\circ}$ angle. This can result in early detection of problem and after analysis proper diagnosis can be carried out without leaving single possibility of 
failure unchecked or unnoticed. In turn resulting in increasing the uninterrupted operating hours, reducing possibility of unscheduled overhauling, increase in life time of equipment, increase in consistency of equipment efficiency with smooth functioning, and no major catastrophic loss.

\section{REFERENCES}

[1] Condition Monitoring of Steam Turbines by Performance Analysis by Ray Beebe, JQME, Vol.9, pp.90-120, 2003.

[2] Theory and Practice of Infrared Technology for Nondestructive Testing by X. P.V. Maldague, New York, John Wiley \& Sons, pp. 54-140, 2001.

[3] Mojeswara Rao Duduku, Kavuluri Lakshmi Narayana, Kavuluri Venkata Ramana and Chintalapati Sridhar Yesaswi, Development of an Expert System for Condition Monitoring of Submarines Using IR Thermography, International Journal of Mechanical Engineering and Technology, 8(4), 2017, pp. 26-33.

[4] Dr.A. S. R. Murty, K. S. S. Satish and K. V. Narendra, Condition Monitoring of Turbine Using IOT, International Journal of Mechanical Engineering and Technology, 9(4), 2018, pp. $433-441$.

[5] WeDineshkumar. C and Subramanian. M, Experimental Investigation of Onboard Driver Condition Monitoring System for Passenger Vehicles, International Journal of Mechanical Engineering and Technology, 9(6), 2018, pp. 304-311 ar Particle Atlas by Anderson, D. Report NAEC-92-163, 1982.

[6] L.B. Bhuyar, S.V. Kshirsagar, G.K. Awari, A.S. Padalkar, Sinhgad College of Engineering, Off Sinhgad Road, Pune, Fault Detection And Condition Monitoring Of Machine-Structure: Review, International Journal of Mechanical Engineering and Technology (IJMET), 2010, Volume: 1, Issue: 1, Pages: 166-181.

[7] Dr. A S R Murthy, Y.K.V Priya Ram and K. Sai Krishna, Fault Diagnosis of Pump-Motorset by using Condition Monitoring and IoT Technique, International Journal of Mechanical Engineering and Technology 9(4), 2018, pp. 828-836.

[8] Pravin P. Joshi and M.R.Bachwad, Condition Monitoring of Induction Motor with A Case Study, International Journal of Electrical Engineering \& Technology (IJEET), Volume 6, Issue 6, June (2015), Pp. 10-15

[9] Power Plant Performance Monitoring by Rodney R.Gay. R-Squared Publishing, Woodland, CA, 2004.

[10] B.R. Manju, A. Joshuva and V. Sugumaran, A data mining study for condition monitoring on wind turbine blades using hoeffding tree algorithm through statistical and histogram features, International Journal of Mechanical Engineering and Technology 9(1), 2018. pp. 1061-1079

[11] Steam Turbine Condition Monitoring by Vibration Analysis by H. A. Searle, PTSAST, pp. 100-108, 2007.

[12] Harindharan Jeyabalan, Ching Sheng Ooi, Kar Hoou Hui, Meng Hee Lim and Mohd Salman Leong. An Improved Turbomachinery Condition Monitoring Method Using Multivariate Statistical Analysis. International Journal of Mechanical Engineering and Technology, 8(5), 2017, pp. 1147-1159. 